\title{
SAMPLING TECHNIQUES FOR ISOLATING TRUNK DISEASE FUNGI FROM A NELSON VINEYARD
}

\author{
D.C. MUNDY ${ }^{1}$, S.G. CASONATO² AND M.A. MANNING ${ }^{2}$
}

\author{
${ }^{I}$ The New Zealand Institute for Plant \& Food Research Limited, Marlborough \\ Wine Research Centre, P.O. Box 845, Blenheim, New Zealand \\ ${ }^{2}$ The New Zealand Institute for Plant \& Food Research Limited, Mt Albert \\ Research Centre, Private Bag 92169, Auckland Mail Centre, New Zealand
}

Corresponding author:dmundy@hortresearch.co.nz

\begin{abstract}
A trial was conducted of two different sampling techniques (destructive and a nondestructive) undertaken at three different times to ascertain the fungal population associated with trunks of grapevines. A Nelson vineyard was surveyed in October 2007 using a coring method on 5 vines, and 105 vines were subsequently sampled in July and October 2008 using a cross-section sampling method. Botryosphaeria, Cylindrocarpon, Eutypa and Phomopsis were isolated on all occasions, regardless of method. The detection of other fungi varied with sampling technique and time taken. Differences in isolations between methods and timings of sample collection reflect the heterogeneous distribution of the fungi within the trunks of old vines. The core sampling technique was sufficient to determine fungi associated with symptomatic and asymptomatic vines. The more destructive technique, where cross-section samples were taken, gave similar results but required more resources. If isolations are to be collected from vines, then the method, timing and sample size need to be considered and standardised.
\end{abstract}

\section{DISTRIBUTION OF BOTRYOSPHAERIA SPP. INFECTION IN DIFFERENT GRAPEVINE NURSERY MATERIALS IN NEW ZEALAND}

\author{
R.G. BILLONES, E.E. JONES, H.J. RIDGWAY and M.V. JASPERS \\ Lincoln University, PO Box 84, Lincoln University, Canterbury, New Zealand \\ Corresponding author: billoner@lincoln.ac.nz
}

The aim of this research was to test different grapevine nursery plant materials from different nurseries around New Zealand for presence of Botryosphaeria species. Tissue samples $(0.5 \mathrm{~cm})$ were cut from surface-sterilised grapevine stem samples [apparently healthy grafted plants, failed grafted plants (or Grade 2 plants), scion and rootstock cuttings of different varieties] collected from nine grapevine nurseries around New Zealand for isolation onto potato dextrose agar plates. The Botryosphaeria-like isolates were identified by conidial characteristics and molecular methods. Of the propagation materials and plants received, 23\% had Botryosphaeria infection. The majority of Botryosphaeria spp. (49\%) were isolated $1 \mathrm{~cm}$ above or below the graft unions of failed/ Grade 2 and Grade 1 plants, but also in the scions (10\%) and the rootstocks (3\%) of the grafted plants. The scion and rootstock cuttings collected from the mothervines had $17 \%$ and $21 \%$ of the Botryosphaeria infections, respectively, mostly from the middle and basal parts of the cuttings. The distribution of Botryosphaeria spp. on different parts of the plants was statistically significant using a Pearson Chi-square test $(\mathrm{P}<0.05)$. These results show that Botryosphaeria species are present in grafted plants in New Zealand, indicating that some of the infections in vineyards may originate in the propagation nurseries. 